\title{
Aller en avant! Moving forward! Results of the CHLA/ABSC 2013 Membership Survey
}

\author{
Charlotte Beck and Jeff Mason
}

\section{Background}

The Canadian Health Libraries Association/Association des bibliothèques de la santé du Canada (CHLA/ABSC) Board of Directors periodically explores the position of the Association vis a vis its membership and the health information profession at large to inform the Association's strategic planning and future direction.

To better understand and prepare for the changes observed and experienced in the information and library environments, the CHLA/ABSC Board of Directors undertook an in-depth approach to its strategic planning process for 2014-2018. As with the Association's previous strategic plans in 2008 and 2010, consultation with members was viewed as critical for the Board to address emerging trends and determine how to best support members. Following previous planning processes the Board agreed to elicit member input via a survey. In addition to the survey, the Board also conducted a Strengths, Weaknesses, Opportunities, and Threats (SWOT) analysis with the Chapter Presidents during the 2013 annual conference. For the first time, a library consultant was employed to help guide the process and facilitate the creation of the strategic plan. This combined methodology allowed the Board to identify critical issues, whilst ensuring that CHLA/ABSC members were given the chance to participate in the strategic planning process, both formally and informally. This paper aims to provide a summary of the results of the membership survey that took place in August and September 2013.

\section{Objectives}

The Board of Directors identified the following objectives for the 2013 membership survey:

(1) to uncover current trends and issues of importance to health librarians in Canada,

(2) to understand the issues and strategic directions of members' parent organizations,
(3) to understand clearly what CHLA/ABSC must do to respond to emerging challenges in our field,

(4) to determine the value of the services that the Board currently provides to CHLA/ABSC members,

(5) to share critical information about CHLA/ABSC and its individual chapters,

(6) to determine the demographics of the membership, and

(7) to understand the nature and value CHLA/ABSC members ascribe to competing library associations.

\section{Methods}

The development of the survey was an iterative process. Previous CHLA/ABSC surveys were used to provide historical context [1,2], and specific questions were carried over from these to allow comparison over time. Two new questions, which were specifically related to strategic planning, were included. These were designed to collect data on the priorities of members' parent organizations and to discover which associations are competing for members' dues and time.

In the fall of 2013, a bilingual (French and English) survey was created using FluidSurveys (Fluidware, Ottawa, $\mathrm{ON})$. The survey was reviewed and tested before distribution by all members of the Board and the strategic planning facilitator.

The survey consisted of 25 questions and employed a variety of formats such as multiple-choice, rating scales, and open-ended questions. The Board was especially interested in gathering the narrative comments of respondents and ensured that adequate opportunity was given to accomplish this goal. Branching and survey logic were used to target specific questions to different groups of respondents once they had identified themselves A copy of all survey questions is available for review in Appendix A.

The final survey was distributed directly to CHLA/ ABSC members in August 2013 by email. Invitations were also sent to the CANMEDLIB and CHLA/ABSC Chapter Presidents' listservs for distribution to Chapter members,

Charlotte Beck ${ }^{\mathbf{1}}$. Woodward Library, University of British Columbia, Woodward Library, 2198 Health Sciences Mall, Vancouver, BC, V6T 1 Z3.

Jeff Mason. Research \& Health Information Services, Health Sciences Library \& Archives, Regina Qu'Appelle Health Region, 0B-Regina General Hospital, 1440-14th Avenue, Regina, SK, S4P 0W5.

${ }^{1}$ Corresponding author (e-mail: charlotte.beck@ubc.ca) 
and they were also posted on the CHLA/ABSC website, Facebook, and Twitter. The original deadline of 26 August 2013 was extended to 7 September 2013 to accommodate summer vacations and the public holiday. All responses were collected anonymously. As an incentive to participate, all respondents were given the option to have their names entered into a separate draw for an iPad mini upon completion of the survey.

\section{Survey results and themes}

A total of 224 responses were received.

\section{Demographics of respondents}

One purpose of the survey was to determine the profile or demographics of the Association so that we could compare this data with previous surveys with reference to age, years of experience, educational levels, position, type of library, and salary. New questions on membership in other associations were added to understand the position and perceived importance of CHLA/ABSC in relation to other library associations.

The demographic information gathered in this survey revealed some interesting trends. The composition of age ranges has remained virtually unchanged since 2001, with $65 \%(n=110)$ being over 40 years of age and $35 \%(n=$ 59) under 40 years of age. In 2010, the largest percentage $(31 \%)$ was in the 50-59 year age group and the second largest $(26 \%)$ was in the 30-39 year age range. These remained essentially unchanged in 2013. When comparing years of experience with 2010 data, there were fewer respondents with $1-5$ years' experience $(29.3 \%$ vs. $23 \%)$, but the percentage of respondents with 6-10 years' experience and more than 15 years' experience remained steady at $22 \%(n=39)$ and $37 \%(n=64)$, respectively. Levels of education remained relatively unchanged with $82 \%(n=143)$ having a Master's degree. For the first time, seven respondents reported doctorate degrees $(2 \%)$.

Nine percent of the respondents said that they worked as library technicians $(n=15), 11 \%$ identified as library administrators $(n=19)$, and $69 \%$ were librarians $(n=$ 119). In the space provided for "other", a few new position descriptions were included such as project manager, evidence specialist, knowledge exchange specialist, and service manager.

Respondents indicated working in the following sectors: hospital $(42 \%, n=72)$, academic $(37 \%, n=64)$, teaching hospital $(19 \%, n=33)$, government $(6 \%, n=11)$, and consortia $(3 \%, n=5)$. In the "other" category, $10 \%(n=$ 17) reported working in public health units, research institutes, health authorities or regions, not-for-profit agencies, or were retired. Additionally, $92 \%(n=156)$ stated that their jobs were specific to the health sciences.

The last question on the survey attempted to elicit information about respondents' involvement with other library associations and asked respondents to rank which membership was most important to them. Previous surveys had indicated that non-members did not join CHLA/ABSC or its Chapters because of other library association memberships. The Board was interested in discovering what unique value CHLA/ABSC has; what competition there was for information professionals' membership dues, time and energy; and what duplication of services could be avoided. CHLA/ABSC was ranked first 77 times (49\%) followed by CHLA/ABSC Chapters 36 times (23\%). The Medical Library Association was ranked first by $14(9 \%)$ respondents.

\section{Association information}

The first question of the survey determined which respondents were members of CHLA/ABSC and which were only members of a CHLA/ABSC Chapter. If they replied that they belonged to neither association, they were directed to the next section (Trends). The purpose of the questions in this section was to learn more about the composition of the membership including the length of time members had belonged to CHLA/ABSC, the membership category to which they belong, and their involvement (if any) in CHLA/ABSC and local chapter activities. As indicated in Table 1, a majority of respondents $(75 \%)$ stated that they were current members of CHLA/ABSC, $30(13 \%)$ were members of their local chapters only, and $26(12 \%)$ were neither members of their local chapter nor of the national organization. The 168 respondents who were current CHLA/ABSC members represented $63 \%$ of the total CHLA/ABSC membership in 2013. Although the percentage of the total CHLA/ABSC membership who completed the survey and the total number of responses for all categories were the highest since 2008, it should be noted that there was also an increase in the number of respondents who were members of their local chapter only, or who were non-members.

Of the respondents who identified as CHLA/ABSC members $(n=168)$, the majority $(64 \%, n=117)$ held regular individual memberships, whereas $18 \%(n=33)$ were institutional members. The remaining survey respondents

Table 1. Response rates to CHLA/ABSC member surveys from 2001-2013

\begin{tabular}{lccccc}
\hline $\begin{array}{l}\text { Survey } \\
\text { date }\end{array}$ & $\begin{array}{c}\text { No. of } \\
\text { responses }\end{array}$ & $\begin{array}{c}\text { \% of CHLA/ABSC } \\
\text { membership who } \\
\text { responded }\end{array}$ & $\begin{array}{c}\text { \% of respondents who } \\
\text { are members of } \\
\text { CHLA/ABSC }\end{array}$ & $\begin{array}{c}\text { \% of respondents who } \\
\text { are only members of a } \\
\text { Chapter }\end{array}$ & $\begin{array}{c}\% \text { of respondents } \\
\text { who were members of } \\
\text { neither }\end{array}$ \\
\hline 2013 & 224 & 63 & 75 & 6 & 13 \\
2010 & 186 & 46 & 84 & 6 & 6 \\
2008 & 140 & 37 & 89 & 18 & 20 \\
2001 & 348 & N/A & 62 & 6 \\
\hline
\end{tabular}


( $n=34$ ) belonged to the honorary, student, retired, sustaining, or unemployed member categories. Sixty-nine percent $(n=111)$ of respondents indicated they had been members for 10 years or less, and $31 \%(n=51)$ indicated that they had been members for more than 11 years. Twenty-two (12\%) respondents chose "not applicable."

An Association's existence is dependent on the contribution of its members. The Board was interested to find out to what extent the membership is involved in CHLA/ABSC activities (e.g., committees, the Board, interest groups). Of the 176 respondents answering this question, $47 \%$ indicated that they had not been previously involved. For those who indicated they were involved, the most frequently cited activity was as a Board or local Chapter executive member $(20 \%)$, followed by contributing to conferences $(19 \%)$, writing for the Association journal (18\%), or membership on a CHLA/ABSC committee $(16 \%)$.

The survey was also designed to obtain information of interest to the Chapters. Specific questions about membership in the local chapters revealed that $80 \%$ of those who were members of CHLA/ABSC were also members of their local Chapter. Reasons given for not becoming a member of a local chapter were diverse and included being members of other library associations (38\%), not knowing about local chapters $(32 \%)$, and not perceiving any value in joining local chapters $(24 \%)$.

\section{Association services}

As in previous surveys, questions were included to obtain information about the perceived value of membership in CHLA/ABSC, which services were most valued, and to discover which services are still needed. To measure the value respondents ascribe to a range of services provided by CHLA/ABSC, a three-point Likert scale was used. The scale ranged from not important ("1") to very important ("3"), and a "no opinion" option was included.

Combining the Association services valued as very important and important, the most valued services were: continuing education, access to the journal, and attending the annual conference (Figure 1). The least valued services were online discussion, the members' directory, and the Association's awards. Respondents were asked 'Are there any services not currently provided that you would find useful?" Of the 39 responses, 9 (23\%) stated none, $11(28 \%)$ indicated an interest in online $\mathrm{CE}$ in either the form of webinars or as a roster of what is available, and $6(15 \%)$ expressed interest in an online community. Other suggestions included mentoring of new librarians, support for personnel experiencing library closures, and more outreach to public health and health promotion sectors.

\section{Communication}

CHLA/ABSC currently uses a wide array of communication strategies and vehicles to communicate with the membership. Respondents were asked to rate which of the current communication methods and networking opportunities were seen as not at all useful, somewhat useful, very useful, or "no opinion". The responses indicated that CHLA/ABSC continues to fulfill its communication mission for health librarians by providing critical information and networking opportunities in various ways. The CHLA/ ABSC website was considered to be the most useful to members. Of note is that online Continuing Education was viewed by $90 \%$ of respondents as most useful or useful for

Fig. 1. Number of respondents who ranked CHLA/ABSC services as very important or important.

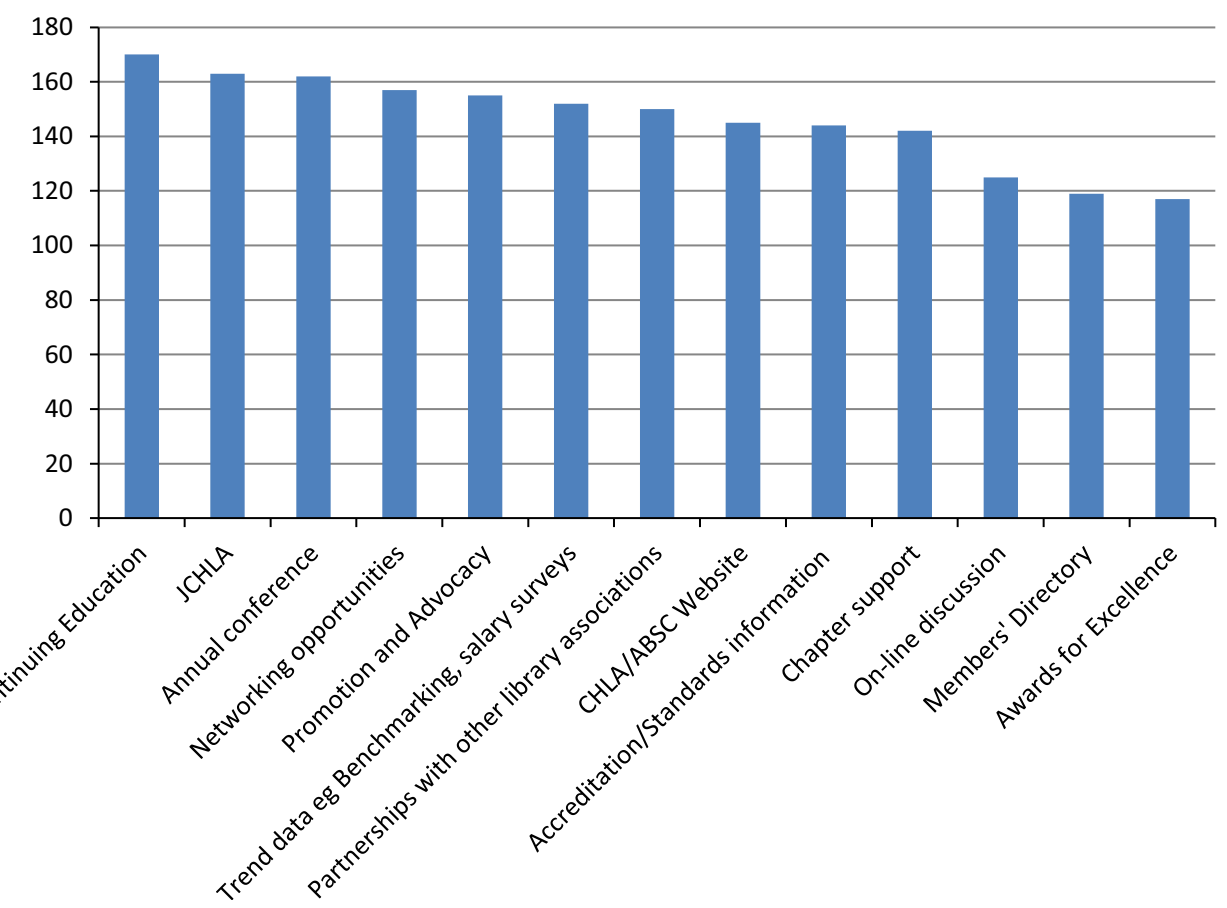


Table 2. Preferred information and networking opportunities provided by CHLA/ABSC

\begin{tabular}{lc}
\hline Communication method & $\begin{array}{c}\text { Ranked by respondents as } \\
\text { "very-useful" or "somewhat } \\
\text { useful" (\%) }\end{array}$ \\
\hline CHLA/ABSC website & $163(95)$ \\
E-news & $155(93)$ \\
Chapter news, websites, and reports & $158(92)$ \\
Online continuing education & $154(90)$ \\
Guidelines & $148(87)$ \\
Special interest groups & $141(85)$ \\
Fact sheets & $146(85)$ \\
Meeting reports & $146(85)$ \\
Membership directory & $134(79)$ \\
Blogs & $133(77)$ \\
Twitter & $97(56)$ \\
Facebook & $87(51)$ \\
\hline
\end{tabular}

this question and that it was also frequently mentioned in the comments in the open-ended section of this question. Social media tools Facebook and Twitter were mentioned as not being freely available in the workplace, thus explaining their rating as least useful. The combined results of the methods rated "most useful" and "useful" are presented in Table 2.

\section{Trends}

All respondents were asked to respond to a set of questions about perceived trends in their libraries and their parent organizations. The Board was interested in gaining an understanding of the environment in which the members operate and its impact on the Association's future. Respondents were asked to select, from a list, up to five trends likely to have an impact on their unit during the next three years and to specify any others not provided. To contextualize this information, the results were analyzed according to the following sectors: academic, hospital, teaching hospital, government, and special/other. Emerging trends varied across the sectors (Table 3 ). The ability to demonstrate value of service was identified as the most impactful for most sectors, but for libraries in the special/other category funding was identified as most important. Funding for the library/unit was viewed as equally important as technologies, particularly mobile access, for all other sectors. Content creation and publishing had the most variability between sectors. Retirements were noted as having the greatest impact in the academic sector.

In addition to discovering which trends are perceived as having an impact, it was felt that intelligence gleaned about the strategies of the parent organizations, as well as those adopted by the library and information units themselves, would assist in a better understanding of the strategic direction the Association needs to take. All respondents were asked three open-ended questions about the main strategies being pursued by their parent organization, the top strategies being pursued by the library or unit, and what changes were seen to be having the greatest impact on library personnel. The results of these, together with the qualitative responses in the trends question, were analyzed to identify themes and develop coding categories. Analysis of the top three strategies being pursued by the library units across all sectors are expressed in a word cloud using "Wordle", wordle.net (Figure 2). As there are both significant and subtle differences between the sectors a discussion of the results by each gives a better understanding of the trends and issues in the environment.

\section{Academic sector $(n=47)$}

Thirty percent of the comments about the parent organization's strategies involved research and included directions such as community-based research, data management, and innovation. Other answers included community engagement, student and aboriginal achievement, and increasing internationalization. Non-traditional teaching in the blended/flexible environment also featured strongly. Another theme was budget cuts and the development of strategies to improve relations with provincial and federal governments to address these.

Correspondingly, the academic libraries are strategizing around staff and budget cuts while "transforming services, collections and facilities to contribute to the success of researchers, scholars and practitioners." These transformations included adapting to distributed learning, increasing e-book purchasing, and reallocating space. Specific strategies mentioned by academic health librarians include building connections among stakeholders and information

Table 3. Most important trends affecting libraries by sector

\begin{tabular}{|c|c|c|c|c|c|}
\hline Trend & $\begin{array}{c}\text { Academic, } \\
\text { no. }(\%) \\
(n=43)\end{array}$ & $\begin{array}{c}\text { Hospital, } \\
\text { no. }(\%) \\
(n=50)\end{array}$ & $\begin{array}{c}\text { Teaching } \\
\text { hospital, no. }(\%) \\
(n=26)\end{array}$ & $\begin{array}{c}\text { Government, } \\
\text { no. }(\%) \\
(n=7)\end{array}$ & $\begin{array}{c}\text { Special/other, } \\
\text { no. }(\%) \\
(n=11)\end{array}$ \\
\hline $\begin{array}{l}\text { Technology: devices/tools (excluding mobile } \\
\text { devices) }\end{array}$ & $13(30)$ & $25(50)$ & $8(31)$ & $3(43)$ & $4(36)$ \\
\hline Mobile devices & $32(74)$ & $33(66)$ & $18(69)$ & $4(57)$ & $6(55)$ \\
\hline Retirements & $17(40)$ & $5(10)$ & $6(23)$ & $1(14)$ & $2(18)$ \\
\hline Funding for your library/unit & $28(65)$ & $35(70)$ & $17(65)$ & $5(71)$ & $10(91)$ \\
\hline Ability to demonstrate value of your service & $36(84)$ & $43(86)$ & $23(89)$ & $7(100)$ & $9(82)$ \\
\hline
\end{tabular}


Fig. 2. Survey themes emerging from responses to Question 14 of the survey: Please list the top 3 strategies your library or unit is pursuing during the next 3 years. (Graphic created using Wordle, wordle.net.)

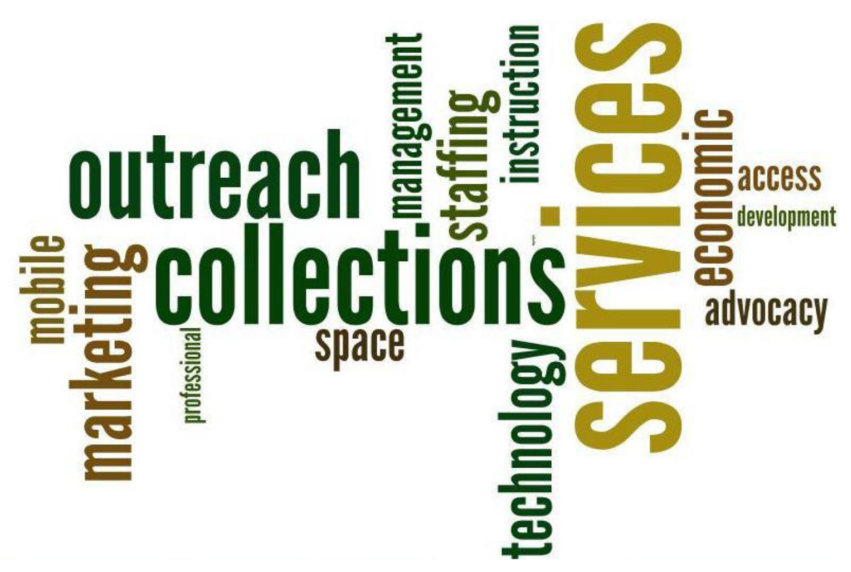

networks and using metrics to communicate the value of the library.

\section{Hospital sector $(n=51)$}

The parent organizations were focused on patientcentered care and patient safety as well as issues such as budgetary restraint, revenue generation, fiscal accountability, and organizational restructuring. Research-based trends incorporating evidence for quality improvement and innovation as well as supporting knowledge translation were also frequently mentioned.

In the hospital libraries sector, as a counterpoint to the academic, there seemed to be a closer connection with the parent organization and its service needs. Although information technology ranked high, strategic directions were related to survival and service enhancement. There was a perceived need to measure outcomes, market services, build networks, and demonstrate a clear return on investment (ROI). Clinical involvement including the introduction and incorporation of mobile devices and point-of-care resources as well as participation in patient education were also frequently mentioned.

\section{Teaching hospitals $(n=28)$}

In the teaching hospitals category, the strategies of the parent institution were similar to those of the hospitals in that they expressed the same concerns related to fiscal accountability, patient-centered care, and the importance of electronic health records. However, with their academic connection, there was a slightly greater emphasis on research and education.

For the libraries in this sector, strategies incorporated those of the academic parent organization as well as the local institution. Technology was mentioned as a strategic area in $79 \%$ of the responses and was related to incorporating new hardware such as mobile devices, delivering virtual services for multisite organizations and outreach programs, and the training of staff and users. Another frequently mentioned theme was marketing the library and gaining a wider visibility by increasing support for evidence-based practices and the inclusion of librarians on multidisciplinary teams. Library management comments included reference to developing more provincewide and multisite services, as well as adapting space to adjust to electronic sources and services.

\section{Other/special libraries $(n=13)$}

Although there were a small number of responses in this section, the organizations had a broad diversity in that they included clinical specialty centres, health regions or authorities, professional associations, or research centres. Common to all was a desire in the strategies of the parent organizations to be successful in their mandate by exercising leadership, using evidence-informed practice, and using digital technology.

In this context, the special libraries emphasized their strategies to support the organizations by adopting technologies, improving budgets, having embedded librarian staff, providing organizational education, and marketing.

\section{Government sector $(n=9)$}

In governmental organizations, the strategies revealed a preoccupation with technologies and electronic resources related to physician engagement and primary health care reform, as well as reorganization and consolidation of services to address budget reductions.

As a corollary, the strategic directions of government libraries included marketing and demonstrating the library's value by supporting the organizations and their stakeholders with training and appropriate resources and by modernizing the access to services.

\section{Summary}

In summary, "LEAN ${ }^{1 "}$ " was frequently used in this section of the survey, both in reference to the strategies of the parent organizations and library units. Other commonalities were "embedded librarians" (on both research and clinical teams), demonstrating value to administrators, reorganization of space, development of new services, staff training, and dealing with the implications of fewer staff.

The effect of environmental changes on personnel roles were similar across all sectors with retirements, both within the unit and in the parent organization. Budget reductions have the greatest effect on staffing.

\section{Conclusion}

The 2013 CHLA/ABSC survey had a dual purpose in that it served as a snapshot of respondents' views of our Association and profession, and it provided intelligence to inform the Association's strategic plan for 2014-2018. The many elements that were gleaned from the survey were used to create a robust plan for the Association, and will continue to be referred to in the future. These data will be important as CHLA/ASBC continues to evolve and as future leaders cope with a changing pan-Canadian landscape of health information sources and services for members.

\footnotetext{
${ }^{1}$ LEAN is a management philosophy and methodology that focuses on creating more value for clients and patients with fewer resources. (Ontario Health Association at http://www.oha.com/ education/continuingeducation/pages/leanhealthcare.aspx)
} 
What seems clear is that continuing education, provided online and using an acceptable platform, will be a critical component of CHLA/ABSC's future strategy. The journal and the annual conference continue to be highly valued by members. Other issues of importance to members include partnering with other health and library organizations. Even though we live in a media-saturated time, many respondents at the time of the survey were unable to access social media within their work environments thus diminishing the importance of these channels of communication and networking. The CHLA/ABSC website, e-news, chapter news, and chapter reports were considered to be the most useful communication tools. Thus, the Board will continue to reach out to our membership using a range of methods to address the wider memberships' varied interests and needs.

As with previous surveys, the response from members and non-members has allowed the Board to achieve its goal of planning for the Association's future within the context in which librarians and health information professionals work. The complete 2014-2018 strategic plan is available online on the CHLA/ABSC website.

\section{References}

1. Dingwall O, Dorgan M, Raworth R, Ticoll M. Taking the pulse of Canadian health information professionals: Canadian health libraries association/association des bibliothèques de la santé du Canada (CHLA/ABSC) 2010 survey. JCHLA [Internet]. 2011. [cited 7 October 2014];32(1):11-15. Available from: http://ejournals.library.ualberta.ca/index.php/jchla/article/view/22525/167532.

2. Kharouba D, Powelson S, Slater L. The value of membership: The CHLA/ABSC 2008 membership survey. JCHLA [Internet]. 2008. [cited 7 October 2014];29(2):47-50. Available from: http:// ejournals.library.ualberta.ca/index.php/jchla/article/view/22844/ 17027.

\section{Appendix A}

Appendix A begins on the following page. 


\section{Appendix A}

\section{CHLA/ABSC Membership Survey 2013}

What does our national Association mean to you? What do you value most? Why join CHLA/ABSC? To help create the Association you want, tell us what value CHLA/ABSC gives you and what you need. There have been significant changes in our information environment since the last national survey in 2010 and the CHLA/ABSC Board would like to learn how it can better meet the needs of its members. Please take a few minutes to complete this anonymous survey and the chance to win an ipad mini. The results will be treated confidentially and used to inform our Strategic Planning session at the next Board meeting in October.

\section{Are you a member of CHLA?}

\begin{tabular}{|l|l|}
\hline$\bigcirc$ & Yes \\
\hline$\bigcirc$ & No, but I am a member of a CHLA Chapter \\
\hline$\bigcirc$ & No. \\
\hline
\end{tabular}

\section{Section A: Association Information}

If you are a member of a CHLA Chapter, but not of CHLA, please select "Not applicable".

\section{How long have you been a member of CHLA?}

\begin{tabular}{|c|l|}
\hline$\bigcirc$ & Less than 1 year \\
\hline$\bigcirc$ & $1-5$ years \\
\hline$\bigcirc$ & $6-10$ years \\
\hline$\bigcirc$ & $11-15$ years \\
\hline$\bigcirc$ & More than 15 years \\
\hline$\bigcirc$ & Not applicable \\
\hline
\end{tabular}

\section{What CHLA membership category do you belong to?}

\begin{tabular}{|c|l|}
\hline$\bigcirc$ & Regular \\
\hline$\bigcirc$ & Student \\
\hline$\bigcirc$ & Institutional \\
\hline$\bigcirc$ & Sustaining \\
\hline$\bigcirc$ & Retired \\
\hline$\bigcirc$ & Honorary \\
\hline$\bigcirc$ & Unemployed \\
\hline$\bigcirc$ & Not applicable \\
\hline
\end{tabular}




\section{How are you currently (in the past year) involved in CHLA activities? Check all that apply}

I have not been involved

Member of a CHLA/ABSC Interest Group (Mentorship, SLAIS Students, Open Access, or Social Media)

Convener of a CHLA/ABSC Interest Group (Mentorship, SLAIS Students, Open Access, or Social Media)

Member of the CHLA/ABSC Board of Directors (Voting or non-voting)

Member of the Board or Executive of local CHLA/ABSC Chapter

$\square$ Official CHLA/ABSC Representative to: Accreditation Canada, Medical Library Association, NRC Knowledge Management Advisory Committee/CISTI, Cochrane network, AFMC Resource Group on Libraries

JCHLA Contributor, peer reviewer, editor

Member of a CHLA/ABSC Committee (Conference Planning Committee, Continuing Education Committee, Research Committee)

Chair of a CHLA/ABSC Committee (Conference Planning Committee, Continuing Education Committee, Research Committee)

Recipient of CHLA/ABSC Funding (Chapter Initiative Fund, Research Grant, Professional Development Grant, Rural and Remote Grant)

2013 CHLA/ABSC Conference contributor (posters, papers, Stat!Ref Talk, invited Fishbowl speaker, moderator, volunteer)

Other, please specify.

\section{Are you a member of a CHLA Chapter?}

\begin{tabular}{|l|l|}
\hline$\bigcirc$ & Yes \\
\hline$\bigcirc$ & No \\
\hline
\end{tabular}

\section{Which CHLA Chapter are you a member?}

\begin{tabular}{|c|l|}
\hline$\bigcirc$ & ASTED-Santé et services sociaux \\
\hline$\bigcirc$ & Golden Horseshoe Health Libraries Association \\
\hline$\bigcirc$ & Health Libraries Association of British Columbia \\
\hline$\bigcirc$ & Manitoba Association of Health Information Providers \\
\hline$\bigcirc$ & Maritimes Health Libraries Association \\
\hline$\bigcirc$ & Newfoundland and Labrador Health Libraries Association \\
\hline$\bigcirc$ & Northern Alberta Health Libraries Association \\
\hline$\bigcirc$ & Northern Lights Health Libraries Association \\
\hline$\bigcirc$ & Ottawa Valley Health Libraries Association \\
\hline$\bigcirc$ & Saskatchewan Health Libraries Association \\
\hline$\bigcirc$ & Southern Alberta Health Libraries Association \\
\hline$\bigcirc$ & Southwestern Ontario Health Libraries \& Information Network \\
\hline$\bigcirc$ & Toronto Health Libraries Association \\
\hline$\bigcirc$ & Wellington-Waterloo-Dufferin Health Library Network \\
\hline
\end{tabular}




\section{Please explain why you are not a member of your local Chapter. Check all that apply.}

\begin{tabular}{|c|l|}
\hline$\square$ & Too expensive \\
\hline$\square$ & No value \\
\hline$\square$ & I am a member of other library association(s) \\
\hline$\square$ & I am no longer in the health sciences library field \\
\hline$\square$ & I am unemployed \\
\hline$\square$ & I am retired \\
\hline$\square$ & I don't live in Canada \\
\hline$\square$ & I didn't know about the local chapter \\
\hline$\square$ & Other, please specify... \\
\hline
\end{tabular}

\section{Section B: CHLA Services and Benefits}

8. CHLA offers many services and benefits to its members. Please rate the importance of the following to you:

\begin{tabular}{|c|c|c|c|c|}
\hline & 1. Not important & 2. Important & 3. Very important & No opinion \\
\hline Continuing Education & $\bigcirc$ & $\bigcirc$ & $\bigcirc$ & 0 \\
\hline Accreditation/Standards information & $\bigcirc$ & $\bigcirc$ & $\bigcirc$ & $\bigcirc$ \\
\hline Promotion and Advocacy & 0 & 0 & $\mathrm{O}$ & 0 \\
\hline CHLA/ABSC Website & 0 & $\bigcirc$ & $\bigcirc$ & $\bigcirc$ \\
\hline On-line discussion & 0 & $\bigcirc$ & $\bigcirc$ & $\bigcirc$ \\
\hline Chapter support & 0 & $\bigcirc$ & $\bigcirc$ & $\bigcirc$ \\
\hline $\begin{array}{l}\text { Partnerships and collaboration with other library } \\
\text { associations }\end{array}$ & $\bigcirc$ & $\bigcirc$ & $\bigcirc$ & $\bigcirc$ \\
\hline Journal of the Canadian Health Libraries Association & $\bigcirc$ & $\bigcirc$ & $\bigcirc$ & $\bigcirc$ \\
\hline Trend data eg Benchmarking, salary surveys & $\bigcirc$ & $\bigcirc$ & $\bigcirc$ & $\bigcirc$ \\
\hline
\end{tabular}

\section{Are there any services not currently provided that you would find useful?}




\section{Section C: Communication}

10. CHLA can fulfill its role by providing information and networking opportunities in a variety of ways. Please indicate how useful each of the following methods is to you.

\begin{tabular}{|c|c|c|c|c|}
\hline & Not at all useful & Somewhat useful & Very useful & No opinion \\
\hline E-news & 0 & 0 & $\bigcirc$ & 0 \\
\hline Blogs & 0 & 0 & 0 & 0 \\
\hline Meeting reports & 0 & 0 & 0 & 0 \\
\hline Fact sheets & 0 & 0 & 0 & 0 \\
\hline Guidelines & $\bigcirc$ & 0 & 0 & 0 \\
\hline Chapter news, websites and reports & 0 & 0 & 0 & 0 \\
\hline Membership directory & 0 & 0 & 0 & 0 \\
\hline Special Interest Groups & 0 & 0 & 0 & 0 \\
\hline Twitter & $\bigcirc$ & 0 & 0 & 0 \\
\hline Facebook & 0 & 0 & 0 & 0 \\
\hline CHLA/ABSC Website & 0 & 0 & 0 & 0 \\
\hline Online Continuing Education & 0 & 0 & 0 & 0 \\
\hline
\end{tabular}

\section{What other networking opportunities would you find useful?}

\section{Section D: Trends}

CHLA wants to support you in the pursuit of your organizations' strategies during the next 3 years. In order to do that we need to know what trends are impacting your organization and what your strategies are.

12. Please list the top 3 strategies that your parent organization (hospital, corporation, university/college, faculty etc.) is pursuing during the next 3 years.

13. Please select up to 5 trends that you see as having an impact on your library or unit during the next 3 years

\begin{tabular}{|c|l|}
\hline$\square$ & Technology: software/applications \\
\hline$\square$ & Technology: devices/tools (excluding mobile devices) \\
\hline$\square$ & Mobile devices \\
\hline$\square$ & Publishing \\
\hline$\square$ & Content creation in your organization \\
\hline$\square$ & Retirements \\
\hline$\square$ & Funding for your library/unit \\
\hline$\square$ & Ability to demonstrate value of your service \\
\hline$\square$ & Other, please specify... \\
\hline
\end{tabular}


14. Please list the top 3 strategies your library or unit is pursuing during the next 3 years.

15. What changes in your work environment will have the most impact on your role in the next 3 years?

\section{Section E: Respondent Profile}

This anonymous demographic information will be used to track trends in membership and will be treated confidentially.

16. What is your age group?

\begin{tabular}{|l|l|}
\hline$\bigcirc$ & Under 20 \\
\hline$\bigcirc$ & $20-29$ \\
\hline$\bigcirc$ & $30-39$ \\
\hline$\bigcirc$ & $40-49$ \\
\hline$\bigcirc$ & $50-59$ \\
\hline$\bigcirc$ & $60-69$ \\
\hline$\bigcirc$ & 70 or older \\
\hline$\bigcirc$ & I do not wish to respond \\
\hline
\end{tabular}

17. How many years of work experience in health-related libraries or as an information professional in the health fields do you have?

\begin{tabular}{|c|l|}
\hline$\bigcirc$ & None \\
\hline$\bigcirc$ & Less than 1 year \\
\hline$\bigcirc$ & $1-5$ years \\
\hline$\bigcirc$ & $6-10$ years \\
\hline$\bigcirc$ & $11-15$ years \\
\hline$\bigcirc$ & More than 15 years \\
\hline$\bigcirc$ & I do not wish to respond \\
\hline
\end{tabular}


18. What is the highest level of formal education in library/information science you have or are completing?

\begin{tabular}{|c|l|}
\hline$\bigcirc$ & Certificate programme \\
\hline$\bigcirc$ & College diploma \\
\hline$\bigcirc$ & Master's Degree \\
\hline$\bigcirc$ & Doctorate \\
\hline$\bigcirc$ & I do not wish to respond \\
\hline$\bigcirc$ & Other, please specify.... \\
\hline
\end{tabular}

19. What is the nature of your employment? Check as many as apply.

\begin{tabular}{|c|l|}
\hline$\square$ & Full-time \\
\hline$\square$ & Part-time (one position) \\
\hline$\square$ & Part-time (multiple positions) \\
\hline$\square$ & Permanent \\
\hline$\square$ & Contract \\
\hline$\square$ & Self-employed \\
\hline$\square$ & Unemployed and seeking work \\
\hline$\square$ & Unemployed and not seeking work \\
\hline$\square$ & Retired \\
\hline$\square$ & Student \\
\hline$\square$ & Other, please specify... \\
\hline
\end{tabular}

\section{What is your primary job position?}

\begin{tabular}{|c|l|}
\hline$\bigcirc$ & Librarian/Information Specialist \\
\hline$\bigcirc$ & Library Technician \\
\hline$\bigcirc$ & Researcher \\
\hline$\bigcirc$ & Vendor \\
\hline$\bigcirc$ & Administrator \\
\hline$\bigcirc$ & Website Co-ordinator \\
\hline$\bigcirc$ & Other, please specify.... \\
\hline
\end{tabular}




\section{What type of library/organization do you work for? Check as many as apply.}

\begin{tabular}{|c|l|}
\hline$\square$ & Academic \\
\hline$\square$ & Consortia \\
\hline$\square$ & Government \\
\hline$\square$ & Teaching Hospital \\
\hline$\square$ & Hospital \\
\hline$\square$ & Public \\
\hline$\square$ & School \\
\hline$\square$ & Special \\
\hline$\square$ & Other, please specify... \\
\hline
\end{tabular}

22. Is your job specific to the health sciences?

\begin{tabular}{|l|l|}
\hline$\bigcirc$ & Yes \\
\hline$\bigcirc$ & No \\
\hline
\end{tabular}

23. As of July 1, 2013 what is your gross annual salary (before taxes and other deductions)? Amounts are in Canadian dollars. International respondents please adjust accordingly

\begin{tabular}{|c|l|}
\hline$\bigcirc$ & Not currently earning \\
\hline$\bigcirc$ & $\$ 0-39000$ \\
\hline$\bigcirc$ & $\$ 40000-\$ 49999$ \\
\hline$\bigcirc$ & $\$ 50000-\$ 59000$ \\
\hline$\bigcirc$ & $\$ 60000-\$ 69000$ \\
\hline$\bigcirc$ & $\$ 70000-\$ 79999$ \\
\hline$\bigcirc$ & $\$ 80000$ or higher \\
\hline$\bigcirc$ & I do not wish to respond \\
\hline
\end{tabular}

24. What other library associations do you belong to?

\begin{tabular}{|c|l|}
\hline$\square$ & Medical Library Association (MLA) \\
\hline$\square$ & Chapter of MLA \\
\hline$\square$ & Canadian Library Association (CLA) \\
\hline$\square$ & Other national or international association. Name: \\
\hline$\square$ & Provincial association. Name: \\
\hline$\square$ & Other, please specify... \\
\hline
\end{tabular}




\section{Which membership is the most important to you?}

\begin{tabular}{|c|c|}
\hline First & $\begin{array}{l}\text { CHLA/ABSC } \\
\text { CHLA/ABSC Chapter } \\
\text { MLA } \\
\text { MLA Chapter } \\
\text { CLA } \\
\text { Other national or international association } \\
\text { Provincial association }\end{array}$ \\
\hline Second & $\begin{array}{l}\text { CHLA/ABSC } \\
\text { CHLA/ABSC Chapter } \\
\text { MLA } \\
\text { MLA Chapter } \\
\text { CLA } \\
\text { Other national or international association } \\
\text { Provincial association }\end{array}$ \\
\hline Third & $\begin{array}{l}\text { CHLA/ABSC } \\
\text { CHLA/ABSC Chapter } \\
\text { MLA } \\
\text { MLA Chapter } \\
\text { CLA } \\
\text { Other national or international association } \\
\text { Provincial association }\end{array}$ \\
\hline
\end{tabular}

Thank you for completing this survey. 